\title{
Translated From the Russian
}

\section{Infektsionnye Psikhozy}

\section{Infection Psychoses}

\section{T. P. SIMSON}

The original article in Russian appeared in Zhurnal nevropatologii i psikhiatrii imeni S.S. Korsakova (Journal of Neuropathology and Psychiatry imeni S. S. Korsakov), volume 56, pages 389-394, 1956. It was translated by the Russian Scientific Translation Program of the National Institutes of Health, Public Health Service.

IN $\mathrm{N}$ the evaluation of the acute infection psychoses, Soviet psychiatrists adhere to the point of view that the character of the external influence is not immaterial to the structure of the pathological conditions which are combined under the name "exogenous psychoses" and that definite typical main syndromes are characteristic of various infections (1-3). However, it is becoming progressively more obvious that the characteristics of the clinical picture at various stages of the course of the process, chiefly during the initial period and during the final period of the disease, are of much greater significance in establishing the typical features of one infection psychosis or another.

At the height of the infection psychosis, when various phases of protective inhibition of the cerebral cortex are observed, the psychotic states induced by various infections are very similar.

Previously, Bonhoeffer's conception predominated abroad. There are certain disagreements between authors on the problem of pre- disposition. Stransky, based on the Meinertian "amentiagrupp" nomenclature, combines the acute infection, the toxic psychoses, and even psychoses occurring on the background of somatic diseases and exhaustion in this group (4). Stransky sees no essential differences within this broad group, and if any are found they are determined, in his opinion, chiefly by the individual characteristics of the personality.

The condition known by the name of "acute delirium" (delirium acutum) has been attracting the special attention of both Soviet and foreign authors. A number of authors express doubt that this condition belongs to the schizophrenia group ("fatal" or "hypertoxic" schizophrenia). In the observations of Ageyeva, Arutyunov, and Slutskina (5), some of the patients with "acute delirium" had in the past had a mental disease; acute delirium occurred in the patients in a temporary association with the infection and was, in the author's opinion, an allergic reaction on a pathological background. Histopathological examination of the brains of patients who died from acute delirium showed that in the severe forms of this disease there are signs of long-existent pathology along with the acute changes (perivascular edema, hemorrhages, swelling of nerve cells) : hyperplastic changes of the pia mater, thickening of the adventitia of the small vessels, hyperplasia of the glia; that is, two processes: a new one and an old one. The infection had acted on a pathologically altered background.

The opinion was expressed that psychoses which occur in connection with streptococcal, staphylococcal, colon bacillus infections, that is, with the ordinary "pyogenic" infections, correspond to the concept of "acute schizo- 
phrenia" (6); these may show the picture of "acute delirium," which is erroneously taken for "acute," "very actively progressive," "fatal" schizophrenia. In patients with the picture of "acute delirium," hemolytic streptococci, staphylococci, and colon bacilli with pathogenic properties have been isolated from the blood and sometimes from the spinal fluid. In the presence of a fatal outcome the same microbes have been cultured from all organs, including the brain.

Belsanti distinguishes symptomatic acute delirium associated with definite known causes and essential delirium which is underlaid by three factors - toxic, constitutional, and emotional ( 7$)$. Both variants of "acute delirium" are associated with an inborn hyperactivity of the cerebrospinal reticular system. Essential delirium is distinguished from symptomatic delirium by the stormy course of the symptoms in the absence of infection or azotemia associated with the hyperproduction of gluco-corticoids which cause protein decomposition. Massive hemorrhages are found in the suprarenals; in the brain, slight inflammatory and acute degenerative changes. The author mentions the progressively increasing azotemia in cases of acute delirium, although in individual patients it may be absent.

On the basis of a study of the brains of 30 patients who died from delirium acutum, Bom emphasizes the importance of hyperactivity of the hypothalamus, which leads to exhaustion of this vitally important center (8). An increased vacuolization occurs in the paraventricular nucleus and supraoptic nucleus, and chromophobia is noted in the ganglion cells.

In the literature there are indications of the presence of a disseminated degenerative process in delirium acutum, chiefly in the area of the third ventricle, which is manifested in the form of small perivascular hemorrhages.

All the authors mentioned agree on the fact that in "acute delirium" the adaptive functions of the organism are impaired. Lingjaerde believes that in "acute delirium" we can speak of a psychosomatic process which is expressed in a reaction similar to a crisis in Addison's disease (9).

While justified in many cases of delirium acutum, the arguments of a number of authors for the inflammatory nature of this disease do not necessarily eliminate the concept of a fatal schizophrenia.

Rozenberg has done considerable work in the study of the characteristics of psychoses in the chronic and latent infections $(10,11)$. An analysis of the data of his observations on patients with conditions such as malaria, brucellosis, tularemia, rheumatic fever, and wound infections, has shown that chronic infectious psychoses are characterized by a distinct picture which approximates them to the so-called exogenous psychoses. Their course may be remittent, intermittent, or relapsing.

Repeated psychoses not uncommonly occur in the presence of a weak general somatic reaction; increase of the latter can sometimes eliminate the psychosis. The pathogenesis of these psychoses is complex; here, there are also allergic signs as a result of sensitization of the organism and weakening of the cerebral cortex under the influence of prolonged stimulation, which brings about an inadequate neural regulation of somatic processes in the organism.

The condition of the defensive mechanisms, the type of nervous system, the sensitization by a series of external, even if minimal, influences during the life of the patient are of particular significance in chronic infections accompanied by somnolence. According to A. Z. Rozenberg's observations, in those patients in whom anxietydepressive, depressive-hallucinatory, depressive-hypochondriacal states, or paranoid or catatonic syndromes predominated in the picture of the psychosis, consciousness remained intact. Psychosis initially can be manifested in very acute pictures, can proceed subacutely, and finally, in a wave-fashion, gradually becoming quiescent; as a result of it, residual encephalitic states may occur.

The periodicity of the course may be explained, in the author's opinion, on the basis of N. S. Vvedenskiy's teaching of parabiosis. The summation of prolonged and weak stimuli leads to the periodic occurrence of parabiotic inhibition. In the presence of an alternating course, contrasting states alternate: manic and depressive, stuporous and expansive. The author believes [it is hard to agree with this] that whereas the central nervous system shows a reaction in a somniferous infection, the somatic sphere is 
apparently not involved; allergic reactions (such as blood changes and erythema) are distinctly expressed. Among the latent infections on the background of which psychosis has arisen, mention is made of osteomyelitis, malaria, brucellosis, and infection of unknown etiology.

Of 100 patients observed by the author, 42 became sick repeatedly, which attests to the marked change in their reactivity. Freezing, burns, bruises, and excitement contributed to the occurrence of the psychosis.

The author separates the chronic psychoses in latent infections both from schizophrenia and from manic-depressive psychosis, advancing such criteria as fatigability, somnolence, hallucinatory experiences at night, lability of the emotions, polymorphism of the clinical picture, etc.

By establishing the general rules and regulations of the course of psychoses in latent infections, A. Z. Rozenberg certainly does not deny the unusualness which various infections introduce into the clinical picture of psychosis. $\mathrm{He}$ mentions typical features proper to psychosis in chronic malaria, tularemia, rheumatic fever, tuberculosis, and suppurative infections.

A study of psychoses in infections of chronic course is being extensively carried out abroad. However, we have encountered almost no comparative evaluation of these psychoses from the point of view of the typical character of certain clinical pictures for one or another infection. This is demonstrated by the evermore considerable popularity of Bonhoeffer's concept.

Chistovich and his co-workers are trying to approach the problem of schizophrenia on the basis of a study of infections. The author believes that during psychoses in conditions such as brucellosis, rheumatism, and suppurative infections, it is possible for schizophrenic disorders to arise with transition into schizophrenic damage. The author has in mind grave chronic psychoses with the prolonged sluggish course of rheumatism in tonsillitis, in otogenous and postnatal infections (12), and in streptococcal and staphylococcal infections.

Chistovich $(6,13,14)$ believes that the psychosis which develops in chronic infections, which represents "a model" of schizophrenia, is in no way different from "the original"; that "fatal," "very active" schizophrenia is an acute toxic-infectious septic psychosis with a hyperergic reaction and the depression of all the defensive functions of the organism.

In Gruhle's work, "Symptomatic Psychoses," attention was given to the so-called "symptomatic" schizophrenias (15). The author distinguishes the following: exogenous diseases combined with real schizophrenia; diseases in which a latent schizophrenic process is shown; diseases in which a readymade syndrome of schizophrenic character is found in a disturbed personality; diseases producing schizophrenic symptoms.

The author believes that only in the last case should we speak of symptomatic schizophrenia. We can hardly agree with these views.

Of the various infections to which considerable attention has been given in recent years, rheumatic fever should be put in first place. As is well known, rheumatic fever morbidity, which decreased during the war years, has subsequently increased. In the Soviet literature a number of works have appeared in which, in addition to a study of the rheumatic psychoses from new theoretical standpoints, the psychopathology is presented in chorea minor and in the nonchoreic forms of rheumatic brain disease $(6,9,16-20)$.

Rheumatic psychoses most often occur stormily; however, chronic rheumatic psychoses are also encountered which sometimes pass into a mental deficiency stage.

In the acute phases of rheumatic psychoses the most frequent syndromes are the following: depressive-hypochondriacal, hallucinatory-paranoid, and catatonic. The latter is most often encountered in chorea minor (16, 17).

Disturbances in consciousness are characteristic of the acute stages of rheumatic psychosis. At first, these are dreamlike, oneiroid states which occur in connection with the transition into the sleep; afterwards, the periods of disordered consciousness lengthen, including the daytime hours. Sometimes, elements of delirium are noted. The disturbances mentioned not uncommonly are replaced by stupefaction; sometimes, a catatonic state occurs. Emotional disturbances are typical of rheumatic 
psychosis-anxiety, fear, dejection, and paroxysmal disturbances of sensory synthesis. Hypochondriacal disorders, at the basis of which lie changes in intero-, extero-, and proprioception, are very typical.

Afterwards, only depressive-hypochondriacal, hallucinatory-paranoid, and catatonic syndromes are manifested distinctly. The psychosis sometimes acquires a considerable similarity to schizophrenia; nevertheless, a number of criteria have been distinguished for the purpose of differential diagnosis (16).

The course of the psychoses is undulant, which is apparently characteristic of allergic conditions. In various cases the psychosis can lead to mental deficiency; however, usually it lasts from several months to a year or more and ends in recovery.

Study of higher nervous activity has made it possible to establish the fact that the toxic-infectious principle produces a protective inhibition in the central nervous system with various phasic states, the clinical expression of which is a whole gamut of disturbances in consciousness -stupefaction, oneiroid, and delirium states $(18,19,21)$.

In the works of Polish authors-Kolakowska (22, 23), Sinchninska (24), and others, attention is directed both to the psychopathological changes in rheumatic disease and to rheumatic psychoses.

Scheidegger presents data concerning the histopathological examination of the brain in acute rheumatic psychosis which show that rheumatic inflammation of the brain (granuloma of the vessels and intravascular infiltrates) involving chiefly the brain stem underlies it (25). However, similar changes are also observed in the cerebrum.

Facts reported by Bruetsch are of interest (26). The author has found structural changes in schizophrenia specific for rheumatic disease (in agreement with what Beletskiy and Avtsyn (27) and Skobnikova (28) reported in their time).

Much attention has been devoted to the psychic disorders in tuberculous meningitis (2931). All the authors agree that various types of disorders of consciousness (stupefaction, oneiroid states with striking fantasy experiences, visual illusions, twilight states, and coma) are typical of the acute phase of tuberculous meningitis. Because of the extensive application of antibiotics, two-thirds of the patients recover; this permits a study of the dynamics of the psychotic states.

Long-lasting but not always gross disorders of consciousness with subsequent prolonged amnesia should be considered characteristic of the course of tuberculous meningitis. In patients who apparently have been fully conscious for a long time, amnesia is noted in connection with the events of this period. In the presence of the memory disorder the intellect as a whole practically does not suffer at all. Pathological changes are particularly pronounced in the brain cisterns.

In the field of children's diseases much attention has recently been given to mumps virus meningitis and to chickenpox encephalitis (3235). In the former, very severe headaches, a marked degree of clouding of consciousness, sleepiness, and an impairment of sensory synthesis are noted. In chickenpox encephalitides not uncommonly a picture of a severe comatose state occurs with convulsive attacks. On the basis of his own observations, Nilsly asserts that in chickenpox encephalitis a toxic-allergic reaction of the vascular wall occurs with secondary cerebral involvement (36).

In recent years, the psychopathology of measles (including acute psychotic states) has been worked out in detail, and psychopathological disorders typical of various phases of the course have been established (37). Abroad, this problem has been studied by Solomon, Makman, and West (38), but without any attempts at distinguishing the features typical of this infection.

The problem of dysenteric and scarlatinal psychoses is being worked out (39).

In the acute stage of the disease it is hard to draw a line between the toxic-infectious psychoses, where the psychosis occurs on a background of intoxication, and the psychoses which develop on the soil of encephalitis primarily or secondarily affecting the central nervous system.

The neurological symptomatology is the most reliable criterion, but it can also be transitory and does not always serve as a true sign of organic involvement of the brain. It should be 
kept in mind, as I. P. Pavlov often emphasized, that there is a possibility of transition of functional into organic, and it is difficult to set a boundary line between them.

In the solving of the problems of infectious psychoses by Soviet psychiatry, pathophysiological methods of investigation are being used on a progressively broader scale with the application of the motor method and speech reinforcement in the A. G. Ivanov-Smolenskiy method, the salivation method, chronaximetry, and electroencephalography $(21,40,41)$. The comprehensive study of mental disorders in infections is being conducted in a progressively more complete fashion (for example, the comprehensive study of children with a neurovirus infection occurring with sensory disorders). The reactivity of the body is being studied widely. All this is making it possible to investigate more thoroughly the pathogenetic mechanisms in the infectious psychoses and the defensive properties of the organism.

The treatment of the infectious psychoses is various. In those cases where the character of the infection is known, casual therapy is prescribed; recently, various antibiotic combinations are being used more and more extensively. In the acute stage of the psychosis, along with the fight against dehydration of the body and regular diet, antihistamines and suprarenal and sex hormones are being used. According to the data in the literature, cortisone has proved to be particularly effective in intensifying the adaptive mechanisms of the organism (9). Electric shock, cardiazol shock, insulin coma widely used abroad for the treatment of acute infectious psychoses cannot be convincingly grounded theoretically.

Further study of the infectious psychoses should proceed along the lines of establishing the typical features introduced by various infections into the clinical picture of the psychosis (careful study of the pathomorphological changes proper to infectious psychoses of different etiologies is also needed) and along the lines of perfecting the pathophysiological, biochemical, and immunological methods of study which will permit us to become more familiar with the pathogenetic mechanisms of infectious psychoses and to elaborate rational methods of therapy on this basis.

\section{REFERENCES}

(1) Gilyarovskiy, V. A.: Old and new problems of psychiatry. Moscow, 1946.

(2) Galach'yan, A. G.: Vrach. delo [Physician's Affairs], 1947, No. 8, pp. 683-688.

(3) Ravkin, I. G.: Nevropat. i psikhiat. [Neuropathology and Psychiatry] 1947, No. 6, pp. 26-32.

(4) Stransky, E.: Wiener klin. Wchnschr. 1951, Nos. 35 and 36.

(5) Ageyeva, A. N. Arutyunov, Ye. S., and Slutskina, P. I. : Zhur. nevropat. i psikhiat. 1955, Nos. 2-6.

(6) Chistovich, A. S.: Zhur. nevropat. i psikhiat. 53 : 248-258 (1953).

(7) Belsanti, R.: Lav. nevro. psikhiat. 13: 1953.

(8) Bom, F.: Ueber die Neurohistologie und Physiologie akuter letaler Psychosen mit einer vorlaeufigen Mitteilung ueber das Untersuchungsergebnis von 30 Gehirnen von Delirium acutum Verstorbenin Patienten. Nord. psykiat. medlembsbl. (1953) 7 .

(9) Lingjaerde, O.: Nord. med. 51: 742-746 (1954).

(10) Rozenberg, A. Z. : Nevropat. i psikhiat. $10: 34-40$ (1952).

(11) Rozenberg, A. Z. : Nevropat i psikhiat. 55: 575580 (1955).

(12) Boyko, M. G.: In Theses of the proceedings of the nineteenth scientific session of the Ukrainian Scientific Research Neuropsychiatric Institute. Khar'kov, 1954, pp. 65-66.

(13) Chistovich, A. S. : Zhur, nevropat. i psikhiat. 55 : 843-850 (1955).

(14) Chistovich, A. S.: In Theses of the proceedings of the nineteenth scientific session of the Ukrainian Scientific Research Neuropsychiatric Institute. Khar'kov, 1954, pp. 62-63.

(15) Gruhle, H. W.: Simptomatische Psychosen Handbuch der inneren Medizin. Berlin, Springer, 1953.

(16) Sukhareva, G. E.: Clinical lectures on the psychiatry of childhood. Medgiz, 1955.

(17) Osipova, E. A.: In Problems of the clinic and therapy of mental diseases. Moscow, 1946, pp. 143-155.

(18) Korganova, A. N., and Simson, T. P.: Zhur. nevropat. i psikhiat. 53: 103-107 (1953).

(19) Simson, T. P.: Revmaticheskie psikhoszy detskogo vozrasta. Zhur. nevropat. i psikhiat. 54 : 241-249 (1954).

(20) Mikheyev, V. V.: Cerebral rheumatic fever. Moscow, 1949.

(21) Levintova, S. E., and Makhtinger, A. I.: Vopr. pediatr. i okhr. mat. i detstva [Problems of pediatrics and of protection of mother and child] 20 : 14-18 (1952).

(22) Kolakowska, T.: Neur. neurochir, psychiat. polska, 1953, 3.

(23) Kolakowska, T.: Zaburzenia psychiczne pochodzenia gosćcowego. Neur. neurochir. psychiat. polska. 4 : 407-412 (1954). 
(24) Sinchninska, H.: Neur. neurochir. psychiat. polska, 1954, 4.

(25) Scheidegger, S.: Radiol. clin. (Basel) 22 (1953).

(26) Bruetsch, W. L.: Istopat. sistema nerv. 1954, 1.

(27) Beletskiy, V. K., and Avtsyn, A. P.: In Collection of works on the pathology of mental and nervous diseases. Moscow, 1939, pp. 20-54.

(28) Skobnikova, V. A.: Nevropat. i psikhiat. 19 : 79 82 (1950).

(29) Lapides, M. I. : Nevropat. i psikhiat. 1948, No. 6, pp. 36-41.

(30) Belousova, V. N.: Nevropat. i psikhiat. 1947, No. 2.

(31) Williams, M., and Smith, H. V.: Mental disturbances in tuberculous meningitis. J. Neurol. 17 : 173-182 (1954).

(32) Gansburg, E. E.: Pediatriya [Pediatrics] 1949 , No. 1.

(33) Vovnyanko, I. V.: Pediatriya, 1949, No. 1.
(34) Tsuker, M. B.: Fundamentals of neuropathology of childhood. Moscow, 1947.

(35) Nistri, M.: Sulle complicanze psichiche delle parotite epidemica nelle adulti. Riv. sper. Freniatr. 77 : 369-382 (1953).

(36) Nilsly, I.: Acta pediat. 53: suppl. 95 (1954).

(37) Model', M. M., and Simson, T. P.: Neuropsychiatric disorders in measles. Moscow, 1952.

(38) Solomon, G., Makman, Ch., and West, E. J. : Measles encephalitis. Pediatrics (1953).

(39) Kudryavtseva, V. P.: Zhur. nevropat. i psikhiat. 55: 770-774 (1955).

(40) Balonov, L. Ya., Lichko, A. E., and Traugott, N. N.: Zhur. nevropat. i psikhiat. 55 : 167-181 (1953).

(41) Sandomirskiy, M. I. : Byull. eksperim. biol. i med. [Bulletin of Experimental Biology and Medicine], 1951, No. 8, pp. 132-135.

\section{PUBLICATION ANNOUNCEMENTS}

Address inquiries to the publisher or sponsoring agency. WHO publications may be obtained from the Columbia University Press, International Documents Service, 2960 Broadway, New York 27, N.Y.

The Aged and Aging in the United States: A National Problem. Report of the Subcommittee on Problems of Aging, U.S. Senate, Committee on Labor and Public Welfare. 1960; 186 pages plus 155 appendix pages; $\$ 1.25$. Superintendent of Documents, U.S. Government Printing Office, Washington 25, D.C.

Public Health. The Reference Shelf, Vol. 31, No. 6. Edited by Peter Van Avery. 1959 ; 242 pages; \$2.50. H. W. Wilson Co., New York.

Adventures in Interaction. The story of the National League for Nursing. January 1960; folder. National League for Nursing, 10 Columbus Circle, New York 19.

Aid to Dependent Children. January 1960; 36 pages; 50 cents for single copies, 40 cents each for orders of 25 or more. National Social Welfare Assembly, Inc., 345 East 46th Street, New York 17.
Middle Age-Threat or Promise? Public Affairs Pamphlet No. 294. By Harry Milt. March 1960; 20 pages; 25 cents. Public Affairs Pamphlets, 22 East 38th Street, New York 16.

Research in Patient Care (with special emphasis on comprehensive care of the chronically ill and aging). A report on a meeting of the Committee on Research of the National Health Council. Papers by Faye G. Abdellah, R.N., Ed.D., Doris Schwartz, R.N., and Harold M. Willard, M.D. January 19, 1960; 36 pages. National Health Council, 1790 Broadway, New York 19.

Federal Agencies Financing Research. Complete 1960 guide to Government grants and contracts. November 1959 ; 27 pages ; $\$ 1$. Document No. 14. Social Legislation Information Service, Inc., 1346 Connecticut Avenue, NW., Washington 6 , D.C.

1959 Report of the Scientific Director. By Clarence Cook Little, Sc.D. 1959; 68 pages. Tobacco Industry Research Committee, 150 East 42d Street, New York 17.
The Central Nervous System and Behavior. Translations from the Russian medical literature. Prepared and distributed by the Russian Scientific Translation Program, National Institutes of Health, Bethesda, Md. December 1,$1959 ; 1,051$ pages.

\section{World Health Organization} Water Supply for Rural Areas and Small Communities. WHO Monograph Series No. 42. By Edmund G. Wagner and J. N. Lanoix. September 1959 ; 337 pages ; $\$ 6.75$.

\section{Films}

Radiation: Physician and Patient. Film sponsored by the American College of Radiology and produced by Stephen W. Schwartz, director of Medical Radio and Television Institute, New York. 16 mm., color, 45 minutes. Prints may be obtained from American College of Radiology, 20 North Wacker Drive, Chicago 6 ; American Medical Association, Film Library, 535 North Dearborn, Chicago 10; and U.S. Public Health Service, Washington 25, D.C.; or any State health department. 